\title{
Management of breastefeeding for late preterm infants
}

\author{
Elisa Civardi ${ }^{1 *}$, Francesca Garofoli ${ }^{2}$, Margherita Pozzi ${ }^{1}$, Mauro Stronati ${ }^{1,2}$ \\ From XX National Congress of the Italian Society of Neonatology \\ Rome, Italy. 9-11 October 2014
}

Breast milk is the preferred feeding for all infants. Unfortunately, late preterm infants (LPIs) have a lower rate of feeding at-breast and lower expressed breast milk intake than other infants. [1] In fact, literature documents an increased risk of morbidity and even mortality of LPIs, often related to feeding problems, possibly due to an inadequate support of the breastfeeding. [2]

Born with low energy stores and high energy demands, LPIs may be sleepier and have more difficulty with latch, suck, and swallow. They are at risk for hypothermia, hypoglycemia, excessive weight loss, dehydration, failure to thrive, kernicterus, and breastfeeding failure.

Establishing breastfeeding in LPIs is problematic, due to neonatal physiological, neurological immaturity and due to maternal risk factors leading to delayed lactogenesis II. Mothers may be obese, experienced a cesarean delivery, have pregnancy induced hypertension, diabetes, or been treated for preterm labor. They easily experience anxiety about milk insufficiency and about separation from their babies for medical problems.

Sanitary staff has to encourage the immediate and extended skin-to-skin contact to improve postpartum stabilization of heart rate, respiratory effort, temperature control, metabolic stability, and early breastfeeding, possibly within 1 hour after birth. If the infant is healthy, it's important to allow rooming in and free access to the breast.

It may be necessary to wake the baby up if he/she does not indicate hunger cues, which is not unusual in LPIs. The infant should be breastfed (even with expressed milk) 8 to 12 times/day. It is important observing the baby feeding at breast and showing the mother techniques to facilitate effective latch and adequate support of

\footnotetext{
* Correspondence: e.civardi@smatteo.pv.it

${ }^{1}$ Neonatal Intensive Care Unit, Fondazione IRCCS Policlinico San Matteo, Pavia, Italy

Full list of author information is available at the end of the article
}

the neonate's head. A nipple shield could be recommended. Pre- post-feeding weight may be helpful to assess milk transfer, because a supplementation with small quantities of maternal expressed milk, donor human milk, or formula may be necessary. If supplementing, the mother should pump milk after breastfeeding, 6 to 8 times/day to establish and maintain milk supply. [3]

LPIs developing complications are often discharged early, after successful transition to extra-uterine environment, but before lactogenesis II is fully established. Before discharge, adequate milk intake should be documented by feeding volume or by thriving. One/2 days after discharge, a follow up to check weight, feeding ability and jaundice is recommended.

In conclusion we may say that breastfeeding LPIs is possible, but to achieve this target, an adequate maternal support and a regular neonatal monitoring is required. [4]

\section{Competing interests}

The authors declare that they have no competing interests.

\section{Authors' details}

${ }^{1}$ Neonatal Intensive Care Unit, Fondazione IRCCS Policlinico San Matteo, Pavia, Italy. ${ }^{2}$ Neonatal Immunology Laboratory, Fondazione IRCCS Policlinico San Matteo, Pavia, Italy.

Published: 9 October 2014

\section{References}

1. Machado Júnior LC, Passini Júnior R, Rodrigues Machado Rosa I: Late prematurity: a systematic review. J Pediatr (Rio J) 2014, 90:221-231.

2. Radtke JV: The paradox of breastfeeding-associated morbidity among late preterm infants. J Obstet Gynecol Neonatal Nurs 2011, 40:9-24.

3. Meier P, Patel AL, Wright K, Engstrom JL: Management of breastfeeding during and after the maternity hospitalization for late preterm infants. Clin Perinatol 2013, 40:689-705.

4. Academy of Breastfeeding Medicine: ABM clinical protocol \#10: breastfeeding the late preterm infant $(34(0 / 7)$ to $36(6 / 7)$ weeks gestation) (first revision June 2011). Breastfeed Med 2011, 6:151-156.
() Biomed Central

(c) 2014 Civardi et al; licensee BioMed Central Ltd. This is an Open Access article distributed under the terms of the Creative Commons Attribution License (http://creativecommons.org/licenses/by/4.0), which permits unrestricted use, distribution, and reproduction in any medium, provided the original work is properly cited. The Creative Commons Public Domain Dedication waiver (http://creativecommons.org/publicdomain/zero/1.0/) applies to the data made available in this article, unless otherwise stated. 
doi:10.1186/1824-7288-40-S2-A36

Cite this article as: Civardi et al: Management of breastefeeding for late preterm infants. Italian Journal of Pediatrics 2014 40(Suppl 2):A36.

Submit your next manuscript to BioMed Central and take full advantage of:

- Convenient online submission

- Thorough peer review

- No space constraints or color figure charges

- Immediate publication on acceptance

- Inclusion in PubMed, CAS, Scopus and Google Scholar

- Research which is freely available for redistribution

Submit your manuscript at 